\title{
Editorial
}

\section{Crossroads in Post-Graduate Psychiatry Training in India}

Jayakumar Menon - Consultant in Neuropsychiatry, Geriatric Care Clinic, and Adjunct Faculty, Department of Psychiatry, SRIHER

Suvarna J Kantipudi - Assistant Professor, Department of Psychiatry, SRIHER

Corresponding author :

Dr Jayakumar Menon,

Geriatric Care Clinic, Sri Ramachandra Institute of Higher Education and Research,

Porur, Chennai, Tamilnadu - 600116

Email: drjkmenon@rediff.com

\section{KEY WORDS: Psychiatry, Post-graduate training,}

There has been a plethora of discussions recently to bring about changes in the teaching of Psychiatry at the undergraduate level by various academicians. Much of it revolved around up-skilling teachers in Psychiatry, allocating more teaching hours for the subject in undergraduate curriculum, and moving to practice based learning. ${ }^{(1)}$

The wide chasm in standards of training is even more apparent in specialist training in Psychiatry. Much of the curriculum for training in universities and autonomous institutes in India is redundant and out of touch with the practical realities and demands on practicing psychiatrists. ${ }^{(2)}$ It would not be an exaggeration to state that some of these still cater to the needs of the psychiatrist in the asylum era. It raises the question if the upcoming crop of psychiatrists in India are being competent enough to internalise the growing demands of the field; in conceptualising, formulating, planning and managing psychological issues in as diverse fields as Child psychiatry, Addiction psychiatry, Geriatric Psychiatry, Neuro-psychiatry, End of life and terminal illness related issues, chronic pain management, Psychotherapies etc.

\section{Progress that has happened over the years in psychiatric training program.}

Since the initiation of formal post graduate training in psychiatry at the All India Institute of Mental Health in 1955, there has been tremendous changes in the field of psychiatry. ${ }^{(3,4)}$ These include significant increase in post graduates trained, shift in training centres from specialised psychiatric institutions to general hospital settings, rise of subspecialties like addiction psychiatry, child and adolescent psychiatry and geriatric psychiatry. Medical Council of India (MCI) which gives guidelines for postgraduate training has made many changes like decreasing the beds required to establish a department, decreasing the duration of faculty experience needed to be a post graduate teacher, increasing the number of students that can be admitted under the guidance of a teacher etc. ${ }^{(5,6)}$ MCI also sensitises the faculty in CBM by conducting Curriculum Implementation Support workshops. ${ }^{(5)}$ The recommendations are being implemented only on paper by many institutions merely to retain MCI's approval for running a particular course.It falls short in practice due to lack of appropriate training environment and effective trainers. 


\section{Core issues that plague training in post graduate Psychiatry training in India}

\section{a) Lack of a unified training program and exit exams in Psychiatry}

Most of the leading specialist training programs across the world have an efficient system to monitor, review and improve their core training programs periodically. While MCI gives a broad outline of "curriculum" for postgraduate training, the chaotic university system in India ensures the teaching approaches are widely different and standards not uniform. Even more problematic is the exam system which happens according to the individual preferences of the "examiners".There is no concept of training the examiners or unified examinations to ensure standardisation or quality.The Indian Psychiatric Society, like the Royal College of Psychiatry, is best equipped to develop training standards, and ensure periodic reviews of examination standards in specialist training. To enhance the overall quality of training, collaboration with NGOs working in areas of community mental health, skilled professionals in private practice, guest lectures by subject experts and providing access to eminent teachers/ researchers by creating a post of visiting/adjunct faculties to mentor and inspire trainees need to be considered.

\section{b) Alienation from other fields of medicine}

It might seem unfathomable that psychiatry or psychiatrists are being kept away from mainstream medical fields in the era past the "decade of the brain". ${ }^{7)}$ The competency of trainees in general medical and neurological cases and its interphase with psychiatry is frequently noted to be poor. Moreover, adequate attention is not being given to develop consultation-liaison psychiatry(CLP) in general hospital settings, where interactions with other specialists happen, providing scope for collaborative work and training.

\section{c) Fusion of research and clinical roles.}

Indian specialist training programs seem to assume that skills are innate in the areas of research and clinical care, and expect specialists to tread both the roles equally and mandatorily soon after they complete their training! It has only led to poorer outcomes in both the areas. While mandatory training in research skills is necessary during ones training, to expect world class research outputs from poorly funded and scantily resourced, but overcrowded departments of psychiatry in many training medical college hospitals is simply overambitious. Having specialised research posts for interested faculty, research sabbatical or dedicated time for research work and regular workshops in clinical research and imparting skills for conducting and critically evaluating research need to be considered to address this.

\section{d) Training program that is outdated}

Competency based training is the gold standard across the world in various medical specialties. There has been no concerted efforts to move towards this in Psychiatry Specialist training in India. ${ }^{(8.9)}$ Instead, there is an increasing trend of sub-specialising in the field, only to produce potential "super-specialists" who could compartmentalise brain and start treating without core competencies in psychiatric interviewing or diagnostic formulation. Supervision of the trainees and periodic training of the supervisors for that role is not a practice in India. It is high time advanced training in areas of interest (not as DM courses) be integrated with specialist training. It may require increasing the duration of training years to 5 or 6 years as is the practice in countries with advanced health systems.

\section{e) Gaps in learning}

The incessant push for more post graduate training posts has put extreme demands on the minuscule teachers of psychiatry, who themselves may not have necessary competencies in specific skilled areas in Psychiatry. The commonly deficient areas include Consultation-Liaison Psychiatry, Child Psychiatry, Neuro-psychiatry, Geriatric Psychiatry and Psychotherapies. While the training program lays emphasis on knowledge base in the curriculum, there is no process to evaluate imparting of skills in these areas or assessing competency in a meaningful way. ${ }^{(10)}$ Staged work-place based assessments may need to be considered as a useful addition to one off summative assessment at the end of 3 years.It is worth a debate whether further 2 years of mandatory training post specialist exams is to be added to the training program. This will ensure core competencies are achieved before licence is given to practice as an independent specialist. 


\section{f) Absence of community and rural psychiatry exposure}

Psychiatrists in India concentrate in its megacities. There is no community mental health services established yet, leading to most of the serious mentally ill patients from rural areas seeking help in urban centres. This leads to minimal scope for ensuring regular followup post acute care. The stigma of institutionalisation and alienation form urban ethos keep many patients from seeking help again or discontinue treatment. Home based assessment, Acute crisis intervention approaches in the community, and community based recovery models are all alien to psychiatry trainees in India. Increasing psychiatric beds in district hospitals are helping to bridge the gap in mental health service delivery. This can be integrated with community mental health care services in urban and rural settings.

\section{g) Ethics and Professionalism}

Ability to provide empathetic care, respecting patients privacy and dignity are essential qualities of a medical professional.Much of these traits are learnt by the trainees through role modelling in both formal and informal settings. Little emphasis is placed on analysis of one's own performance by consultants who provide training. Institutional barriers like poor relationships between team members, emphasis on increasing patient load and income generation, and unethical practices in many training centres provide a wrong model for a trainee psychiatrist. Providing trainees a safe place to reflect on real life issues, mandatory training in ethics, enhanced supervision, and imparting professionalism can be part of formative assessments. ${ }^{(1)}$ Public trust on doctors which has plummeted in the recent years can only be revived by inculcating high standards of professional and ethical behaviour among trainees.

\section{h) Cultural learning and adaptation to the society's needs}

There is a general aversion among medical specialists to traditional methods of healing and learning. Psychiatry cannot turn its face away from its inexorable links with culture, which provides the rich milieu for beliefs, practices, faith, illness models and expectations of recovery. A broader dialogue with various disciplines including the arts, literature and sociological sciences form a quintessential backbone to a practicing psychiatrist to relate, understand and assist recovery from the trauma of mental illness for a patient. The existing training programs do not emphasise this aspect at all. ${ }^{(12)}$ Adequate emphasis in this area will help transform the practice of the field by not getting stuck with bio-medical reductionism. Only then can it carry forward the scientific temper in sync with the individual belief systems to bring about a more harmonious and individualised approach to care.

A detailed review of papers that looked critically at the psychiatry training program in India have revealed that some of these issues have been raised by leading experts in specialist training earlier, but not much progressive action was taken over the years. Whether it is the larger problem in health education in India that is reflected in Psychiatric training as well or is it because of lessening interests in core teaching and learning that has led to the current scenario is a matter of debate. Some changes for the better is evident in undergraduate training in Psychiatry, through efforts taken by the Indian Psychiatric society in recent months. More needs to be done by interested individuals and IPS, to embark upon the arduous but critical task of raising the standards of psychiatry training in India on par with the standards of some of the leading countries in mental health care. 


\section{References}

1 Kakunje A, Punnoose VP, Ponnusamy KP, Mysore AV, Daniel SJ. Revisiting postgraduate (PG) psychiatry training in India. Indian J Psychol Med 2019;41:380-7

2 Isaac, M., Ahmed, H. U., Chaturvedi, S. K., Hopwood, M. J., Javeed, A., Kanba, S. Sartorius, N. (2018). Postgraduate training in psychiatry in Asia. Current Opinion in Psychiatry, 31(5), 396-402.

3 Das, M., Gupta, N., \& Dutta, K. (2002). Psychiatric training in India. Psychiatric Bulletin, 26(2), 70-72. doi:10.1192/pb.26.2.70

4 Mohandas E. Roadmap to Indian Psychiatry. Indian J Psychiatry. 2009;51(3):173-9 Raghuraman BS, Nataraj M, Shiva L.

5 Medical Council of India.Guidelines for Competency Based Post graduate Curriculum. [Internet]. Available from: https://www.mciindia.org/CMS/wp-content/uploads/2019/09/MD-Psychiatry.pdf

6 Medical Council of India PG Medical Education Regulations [Internet]. Available from: https://www. mciindia.org/CMS/rules-regulations/p-g-medical-education-regulations-2000.

7 Pietilä, Pekka E.. "Embrace the inevitable : a paradigm shift in history of psychiatry during the Decade of the Brain.” (2019).

8 Grover S, Sahoo S, Srinivas B, Tripathi A, Avasthi A. Evaluation of psychiatry training in India: A survey of young psychiatrists under the aegis of research, education, and training foundation of Indian Psychiatric Society. Indian J Psychiatry. 2018;60(4):445-460.

9 Kishore ANR, Shaji KS, Praveenlal K. Revalidation: Are we Meeting Training Needs? Training and its Influence on the Practice of Child Psychiatry and Psychotherapy. Indian J Psychol Med. 2010;32(1):3-6.

10 Psychiatry trainee stressors in a postgraduate psychiatry training centre in India. BJPsych International. 2019 Aug;16(3):53-5.

11 Bayetti C, Jadhav S, Deshpande SN. How do psychiatrists in India construct their professional identity? A critical literature review. Indian J Psychiatry. 2017;59(1):27-38.1.

12 Addlakha R. 'Indigenisation' not 'Indianisation' of Psychiatry: An Anthropological Perspective. Sociological Bulletin. 2010 Jan 1;59(1):46-68. 